\title{
Investigation of rheological behavior of Kyrgyz traditional food Sary mai
}

\author{
Janyl Iskakova, ${ }^{1, *}$ Jamila Smanalieva ${ }^{2}$ \\ ${ }^{1}$ Kyrgyz-Turkish Manas University, Engineering Faculty, Environmental Engineering Department, Bishkek, Kyrgyzstan, \\ janyl.iskakova@manas.edu.kg, ORCID:0000-0002-1614-3984 \\ ${ }^{2}$ Department of Food, Nutrition and Home Economics / Vocational Didactics, TU Dresden, 01217 Dresden, Germany, \\ jamila.smanalieva@gmail.com, ORCID: 0000-0002-3929-4291
}

\begin{abstract}
A B S T R A C T
In this study, the rheological properties of shelf-stable and calorie-rich traditional product Sary mai, known as ghee were investigated at various temperatures for the first time. It was found that ghee at $20-30^{\circ} \mathrm{C}$ reacted as a non-Newtonian pseudoplastic fluid with yield stress value and flow curves fitted to the Herschel-Bulkley model. With increasing the temperature, ghee becomes more fluid: at $40^{\circ} \mathrm{C}$ the Ostwald-De-Waele model and $50^{\circ} \mathrm{C}$ the Newton model were found as the most appropriate to fit the flow curves. The effective viscosity of ghee samples stored at room temperature decreased from 2.613 to $0.023 \mathrm{~Pa} \cdot \mathrm{s}$ with increasing temperature from 20 to $50^{\circ} \mathrm{C}$. The Arrhenius relationship was employed to estimate the flow activation energy for the ghee samples stored at room and fridge temperatures and was found as $E_{a}=26.3$ $\mathrm{kJ} / \mathrm{mol}$ with $\mathrm{R}^{2}=0.9350$ and $\mathrm{E}_{\mathrm{a}}=29.9 \mathrm{~kJ} / \mathrm{mol}$ with $\mathrm{R}^{2}=0.9223$, respectively. Due to the crystallization of fat globules at low temperature the activation energy, yield stress, consistency coefficient, flow index of ghee stored at fridge temperature was higher than the sample stored at room temperature. The amplitude-sweep was performed at $20^{\circ} \mathrm{C}$ for determining the yield point and the flow point. Obtained parameters provide useful information for the optimization of industrial processes and control of the quality of ghee.
\end{abstract}

\section{ARTICLE INFO}

\section{Research article}

Received: 13.06.2020

Accepted: 15.12.2020

Keywords:

Sary mai,

ghee,

rheological properties,

viscosity,

yield stress,

consistency coefficient,

flow index

*Corresponding author

\section{Introduction}

Previously nomadic, the Kyrgyz people usually used meat or milk-based foods in their diets. Traditionally, cow and mare milk were consumed in Kyrgyzstan. One of the widespread and calorie-rich dairy products Sary mai or ghee is made of cow milk. Ghee (clarified butter, butter oil) is anhydrous milk fat obtained by clarification of cow or buffalo milk fat at a high temperature. According to the literature review, ghee is widely consumed in Asia, Middle East, India, and African countries, therefore, methods of manufacture and characteristics vary [1-4].

According to the home technology of Kyrgyz ghee preparation shown in Fig.1, cow milk butter is melted on a gentle heat (up to $120^{\circ} \mathrm{C}$ ) to evaporate the moisture and to separate milk proteins. Heating is stopped when solid residues (milk proteins), called Chöbögö, start turning brown. Transparent yellow butter oil will be decanted from Chöbögö and can be stored for about one year in ambient temperature due to its low moisture content and the presence of natural antioxidants, such as vitamin E [1].

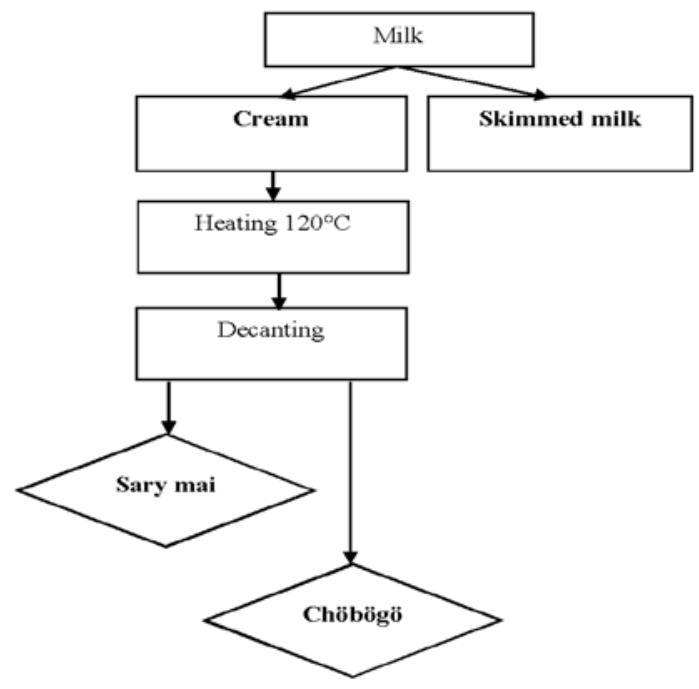

Figure 1. Production scheme of Kyrgyz ghee 
According to Sharma et al. (2010), ghee contains a small amount of free fatty acids, phospholipids, sterols, and their esters, fat-soluble vitamins (A, D, E, and K), carotenoids, carbonyl compounds, hydrocarbons, charred casein, moisture and traces of trace elements like copper and iron [5]. Carbonyls, lactones, and free fatty acids are reported to be the key flavoring compounds of ghee. It may contain high amounts of conjugated linoleic acid, as reported as an anticarcinogen. According to Indian medicine, the consumption of ghee with medicinal plants and herbs helps humans to live longer allows its functional components to pass into deeper tissue levels improving their efficacy and bioavailability in the human body [6].

Traditional Kyrgyz ghee is usually produced in homes, villages, and small-scale industries. Ghee requires established technological parameters to produce on the industrial-scale. Generally, an understanding of the rheological properties of food materials has a direct effect on the optimization of processing stages such as production, handling, storage, and final quality [7]. Understanding the relationship between structure and rheology is crucial for the design of fat products with tailored mechanical functionality [8]. Therefore, the objectives of this study were: (i) to investigate the rheological properties of Kyrgyz ghee; (ii) to determine the best timeindependent model to fit the flow curves of Kyrgyz ghee; (iii) to study the amplitude dependency of Kyrgyz ghee in the range of $20-50^{\circ} \mathrm{C}$.

\section{Materials and methods}

\subsection{Rotational rheological measurements}

For this experiment, 2 ghee samples were purchased from Kyrgyz local markets and stored at room temperature (Sary mai 1) and fridge temperature at $5^{\circ} \mathrm{C}$ (Sary mai 2) until measurement. Composition of ghee according to a producer for melted butter as follows: fats $99.0 \mathrm{~g}$, carbohydrates -0.6 g, proteins $-0.3 \mathrm{~g}$, vitamin A $-0.6 \mathrm{mg}$, and $891 \mathrm{kcal}$ energy in $100 \mathrm{~g}$ of product [9]

During this study of rheological properties of Kyrgyz ghee rotational and oscillatory measurements have been performed. Rheological measurements were carried out by using the rheometer MCR 302 (Anton Paar, Graz, Austria) with concentric cylinder geometry CC27. Each analysis was done at least three times to avoid inaccuracy. The data, obtained from the rheological measurements were analyzed with the supporting rheometer software Rheoplus 32 Multi 6 version 3.40 .

The rotational measurement condition was used to obtain flow behaviors of Kyrgyz ghee by measuring steady shear viscosity $\eta(\dot{\gamma})$ and shear stress $\tau(\dot{\gamma})$ at $20,30,40$, and $50^{\circ} \mathrm{C}$. The measurements were performed in three intervals: I) the shear rate was progressively increased linearly from 2 to $50 \mathrm{~s}^{-1}$ over a span of $90 \mathrm{~s}$; II) the shear rate was constant at a shear rate of $50 \mathrm{~s}^{-1}$; III) the shear rate was progressively decreased from 50 to $2 \mathrm{~s}^{-1}$.

To describe the rheological behavior of ghee, the flow curves were modeled using equations such as Herschel-Bulkley, and Ostwald-De-Waele [10].

1) Herschel - Bulkley:

$$
\tau=\tau_{0}+K \dot{\gamma}^{n}
$$

where $\tau_{0}$ is yield stress, $K$ is the consistency index for the Herschel-Bulkley model, $\dot{\gamma}$ is the shear rate.

2) Ostwald-de Waele (or Power-law):

$$
\tau=K \dot{\gamma}^{n}
$$

where $\mathrm{K}$ is the consistency index $\left(\mathrm{Pa} \cdot \mathrm{s}^{\mathrm{n}}\right)$ and $\mathrm{n}$ is a flow behavior index.

For a Newtonian fluid $\mathrm{n}=1$ and $\mathrm{K}$ is simply the constant viscosity, $\eta$ :

$$
\tau=\eta \dot{\gamma}
$$

The effect of temperature on dynamic viscosity and the activation energy was calculated using an Arrhenius-type equation (Eq. 3):

$$
\ln \eta=\ln A+\left(-\frac{E_{a}}{R}\right) \cdot\left(\frac{1}{T}\right)
$$

Where $A$ is the pre-exponential factor, $R$ is the ideal gas constant $(8.31 \mathrm{~J} / \mathrm{mol} \cdot \mathrm{K}), T$ is the absolute temperature $(\mathrm{K})$. The activation energy $E_{a}(\mathrm{~J} / \mathrm{mol})$ is the energy barrier that must be overcome before the flow process is initiated [11].

\subsection{Oscillatory rheological measurements}

This oscillatory test was carried out with a constant frequency of $0.1 \mathrm{~Hz}$ and variable strain amplitude from 0.01 to $100 \%$ at $20^{\circ} \mathrm{C}$. In this test, first the crossover point $\mathrm{G}^{\prime} / \mathrm{G}^{\prime \prime}$ and an upper boundary of the Linear Viscoelastic (LVE) range were determined.

\section{Results and discussion}

\subsection{Effect of shear rate and temperature on rheological parameters}

The flow curves of ghee samples obtained at 20, 30, 40, and $50^{\circ} \mathrm{C}$ are shown in Figures 2 and 3. The results showed that samples behaved as non-Newtonian pseudoplastic fluid with 
a value of yield stress $\left(\tau_{0}\right)$ at 20 and $30^{\circ} \mathrm{C}$. The sample stored at fridge temperature has the highest consistency coefficient with high yield stress. However, with an increase in temperature the samples tended to shift to a Newtonian fluid at 40 and $50^{\circ} \mathrm{C}$. This behavior is due to a reduction in flow resistance and structural change, the melting of fat globules. The same findings were previously described by Duhan et al. (2018) for Indian ghee at 30 and $36^{\circ} \mathrm{C}$ [12]. Taghizadeh and Razavi (2009) reported that pistachio butter samples show a loss of consistency between 45 and $65^{\circ} \mathrm{C}$ and behaved as a dilatant fluid with an increase in temperature [13].

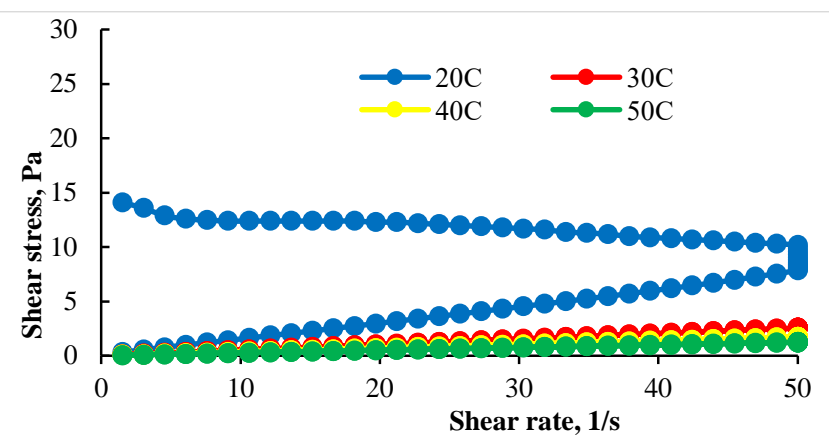

A

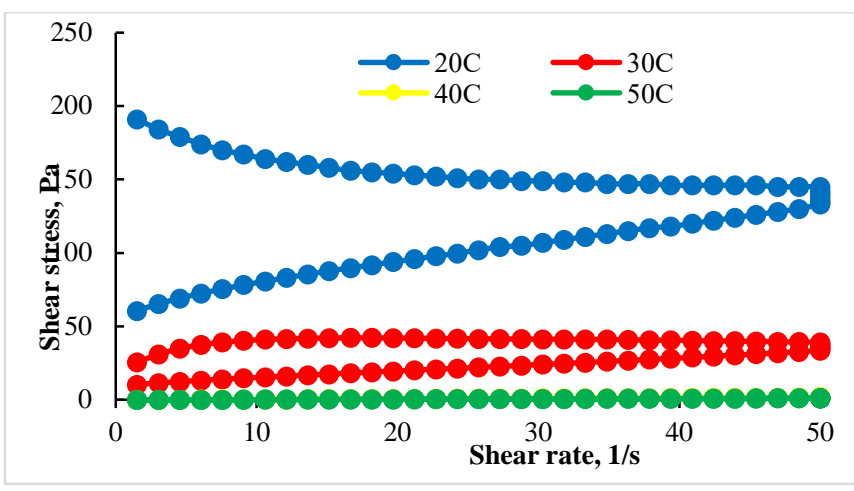

B

Figure 2. Flow curves of ghee samples with up and down curves at 20, 30, 40, and $50^{\circ} \mathrm{C}$ of samples A) Sary mai 1; B) Sary mai 2.

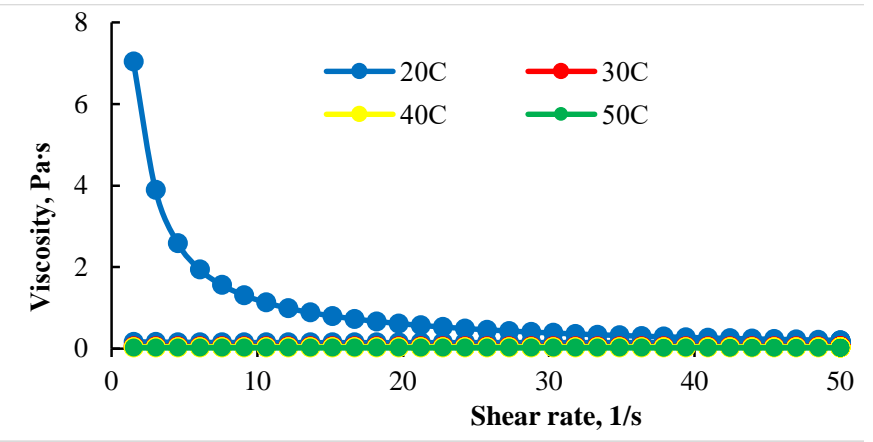

A

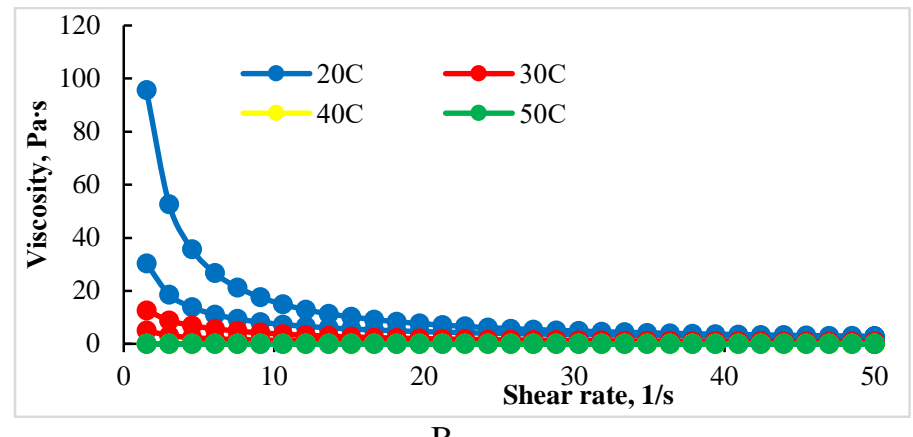

B

Figure 3. Shear rate and dynamic viscosity relationship of ghee samples at $20,30,40$, and $50^{\circ} \mathrm{C}$ with up and down curves A) Sary mai 1; B) Sary mai 2.

Fig. 3 showed the relationship of shear rate and dynamic viscosity of ghee samples was obtained at $20,30,40$, and $50^{\circ} \mathrm{C}$. The viscosity of ghee samples decreased under shear strain and showed shear-thinning behavior at 20 and $30^{\circ} \mathrm{C}$. Three intervals test showed that viscosity equilibrium has not been established between structure degradation and rebuilding. Therefore, it can be concluded that internal network structures were broken down by shearing which leads to degradation of the material. At $40{ }^{\circ} \mathrm{C}$, the viscosity of the up and down curves was nearly the same of both ghee samples and they behaved as a dilatant fluid with flow index $\mathrm{n}=$ 1.0007, which indicated the start of melting fatty acids. Further increase in temperature leads to the fully melting of fat crystals and at $50^{\circ} \mathrm{C}$ both samples of Kyrgyz ghee behaved as a Newtonian fluid. The melting and solidification behavior of fats is crucial in determining the rheological properties of fat and fat-containing foods. Naturally, occurring fats are multicomponent mixtures of triacylglycerols. According to Ronholt et al. (2012) and Moorthy (2018), the interactions between component triacylglycerols govern, broadly, the melting behavior of a complete fat [14-15]. Also, other researchers stated that fatty acid composition directly influences the rheological and thermal of animal fats [16].

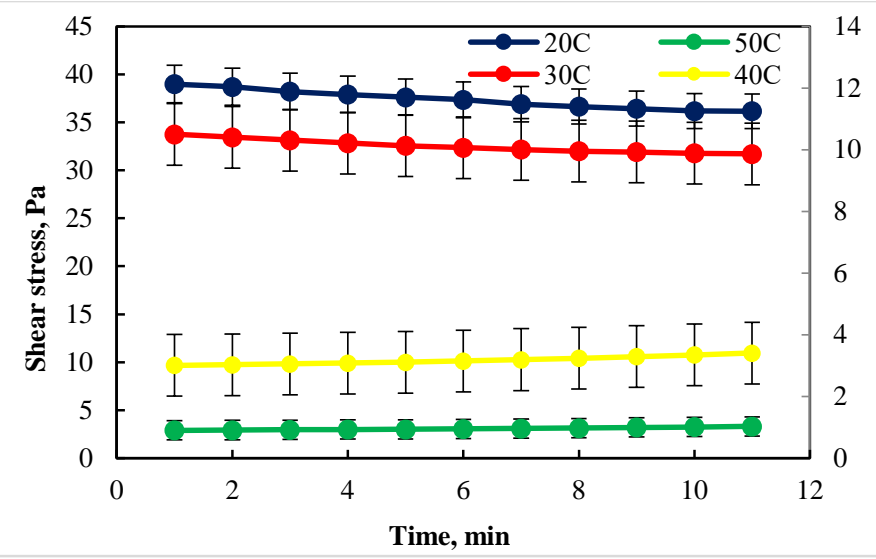

Figure 4. Time-dependent and time-independent flow of Kyrgyz ghee (average values of two samples) 
To analyze the time-dependent flow behavior the second interval of flow curve ghee samples was studied at 20, 30, 40, and $50^{\circ} \mathrm{C}$. The time-dependent flow exists when shearing at 20 and $30^{\circ} \mathrm{C}$ (Fig 6). The hysteresis area between the upward and downward curves of shear rate vs shear stress rheograms at $20^{\circ} \mathrm{C}$ is shown in Table 1 . The highest hysteresis area Ath was at $20^{\circ} \mathrm{C}$ and with the increase of temperature Ath of Sary mai 1 decreased from 2671.70 to $0.49 \mathrm{~Pa} / \mathrm{s}$ and the Ath of Sary mai 2 from 8722.13 to $0.49 \mathrm{~Pa}$.s. The upwards and downwards ramp at 40 and $50^{\circ} \mathrm{C}$ did not differ from each other (see Fig. 2 and 3), therefore, it can be concluded that the sample's behavior is time-independent at these temperatures.

Table 1. Adjustment of experimental data of Kyrgyz ghee to the Herschel-Bulkley and Ostwald-De Wale models

\begin{tabular}{|c|c|c|c|c|c|c|c|c|}
\hline Model & $\mathrm{T}\left({ }^{\circ} \mathrm{C}\right)$ & $\tau_{0}(\mathbf{P a})$ & $K\left(\mathbf{P a}=s^{n}\right)$ & $\mathbf{n}$ & $\mathbf{R}^{2}$ & SD & $\begin{array}{l}\eta_{\text {eff }}(\text { Pa } \cdot s), \\
\text { at } \gamma=50 \mathrm{~s}^{-1}\end{array}$ & $\operatorname{Ath}(\mathbf{P a} / \mathbf{s})$ \\
\hline \multicolumn{9}{|l|}{ Sary mai 1} \\
\hline Herschel-Bulkley & 20 & 53.38 & 4.984 & 0.701 & 0.9988 & 0.72 & 2.613 & 2621.70 \\
\hline Herschel-Bulkley & 30 & 9.23 & 0.692 & 0.902 & 0.9985 & 0.26 & 0.594 & 865.22 \\
\hline Ostwald De-Wale & 40 & - & 0.033 & 1.007 & 0.9999 & 0.00 & 0.034 & 0.31 \\
\hline Newton & 50 & - & 0.023 & 1.000 & 0.9999 & 0.00 & 0.023 & 0.49 \\
\hline \multicolumn{9}{|l|}{ Sary mai 2} \\
\hline Herschel-Bulkley & 20 & 181.78 & 7.812 & 0.813 & 0.9984 & 2.09 & 7.394 & 8722.13 \\
\hline Herschel-Bulkley & 30 & 27.02 & 1.425 & 0.866 & 0.9993 & 0.32 & 1.384 & 1138.91 \\
\hline Ostwald De-Wale & 40 & - & 0.035 & 1.002 & 1.0000 & 0.00 & 0.035 & 0.31 \\
\hline Newton & 50 & - & 0.024 & 1.000 & 0.9999 & 1.24 & 0.024 & 0.49 \\
\hline
\end{tabular}

The rheological parameters are reported as mean and standard deviation of three independent measurements

The down curves were fitted to the Hershel-Bulkley, Ostwald De-Wale, Newton models to describe the flow behavior of the samples. To find the best-fitted rheological model, the estimated statistical parameters such as correlation coefficient $\mathrm{R}^{2}$ and standard deviation SD were compared. The HershelBulkley model was found the most appropriate to fit the flow curves of Kyrgyz ghee at 20 and $30^{\circ} \mathrm{C}$ with $\mathrm{R}^{2}$ ranged from 0.9984 to 0.9988 and the Newton model was best-fitted at 40 and $50^{\circ} \mathrm{C}$ with $\mathrm{R}^{2}$ ranged from 0.9999 to 1 . The yield stress $\left(\tau_{0}\right)$ and the consistency coefficients $(\mathrm{K})$ value obtained by fitting the rotational speed versus apparent viscosity data of down curve to a Hershel-Bulkley (Eq. 1), Ostwald-De Wale (Eq. 2), and Newton models (Eq. 4) are presented in Table 1. The consistency coefficient $\mathrm{K}$ measures the average viscosity of the non-Newtonian fluid and in our study decreases with increasing the temperature from 7.812 to $0.033 \mathrm{~Pa} \cdot \mathrm{s}^{\mathrm{n}}$. The lowest $\mathrm{K}$ value was obtained for samples at $30^{\circ} \mathrm{C}$. Taghizadeh \& Razavi (2009) studied the rheological behavior of pistachio butter at 25 and $35^{\circ} \mathrm{C}$ the Herschel-Bulkley model was found to be the best to describe the rheological property with the coefficient of determination ranging from 0.952 to 0.999 . The consistency coefficient $\mathrm{K}$ of pistachio butter without any emulsifier at $25^{\circ} \mathrm{C}$ was $17.14 \mathrm{~Pa} \cdot \mathrm{s}^{\mathrm{n}}$ and was higher than $\mathrm{K}$ of Sary mai 2 at $20^{\circ} \mathrm{C}$ and was found as $7.812 \mathrm{~Pa} \cdot \mathrm{s}^{\mathrm{n}}$ [13].

The effective viscosity was calculated according to the suitable flow models at a shear rate of $501 / \mathrm{s}$. The effective viscosities of ghee decreased from 7.394 to $0.023 \mathrm{~Pa} \cdot \mathrm{s}$ (sample "Sary mai 2") with increasing temperature from 20 to $50^{\circ} \mathrm{C}$. This behavior could be explained based on the subsequent reduction of fluid viscosity due to the melting of crystals of ghee and shifting of the flow behavior from pseudoplastic to shear-thinning nature without the yield stress with an increase in temperature. These findings are in agreement with Duhan et al. (2018) reported for Indian cow milk (Desi) ghee [12].

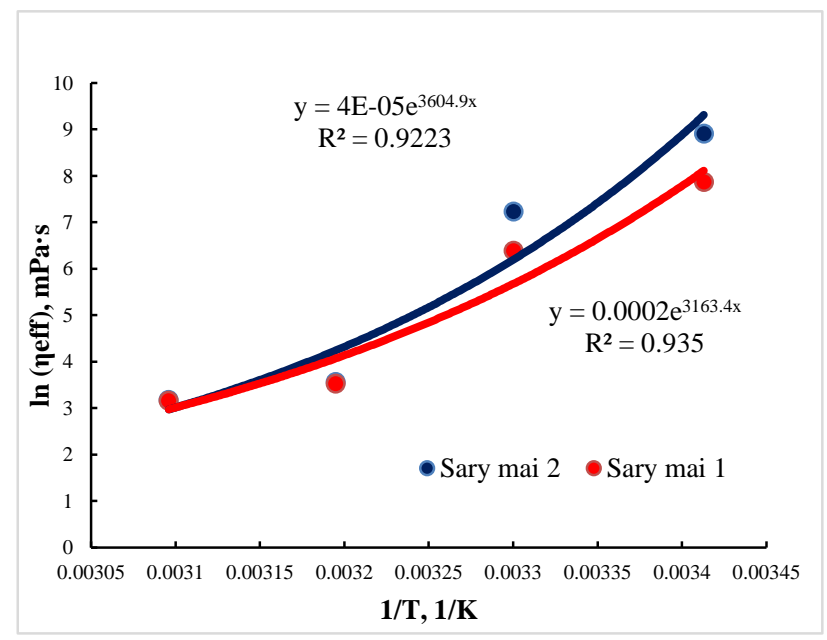

Figure 6. Arrhenius-type model fit for Kyrgyz ghee 
The temperature effect on the viscosity of Kyrgyz ghee was estimated using Eq. 3 for temperatures between 20 and $50^{\circ} \mathrm{C}$. As shown in Fig.6 the activation energy, $\mathrm{E}_{\mathrm{a}}$, and coefficient A were calculated for Sary mai 1 as $26.3 \mathrm{KJ} / \mathrm{mol}$ and 0.0002 respectively, with a correlation coefficient $\mathrm{R}^{2}=0.9350$. For Sary mai 2 the activation energy was found as $29.9 \mathrm{KJ} / \mathrm{mol}$, A was calculated as 0.00004 with $\mathrm{R}^{2}=0.9223$. The high activation energy of ghee indicates that more energy is required for the product flow. Due to the crystallization of fat globules at low temperature the activation energy of Sary mai 2 stored at fridge temperature was higher than the sample stored at room temperature. Taghizadeh and Razavi (2009) calculated the activation energy of pistachio butter at $25-65^{\circ} \mathrm{C}$ at the range between $10.3-52.5 \mathrm{~kJ} / \mathrm{mol}$ [13].

\subsection{Dynamic shear rheological properties}

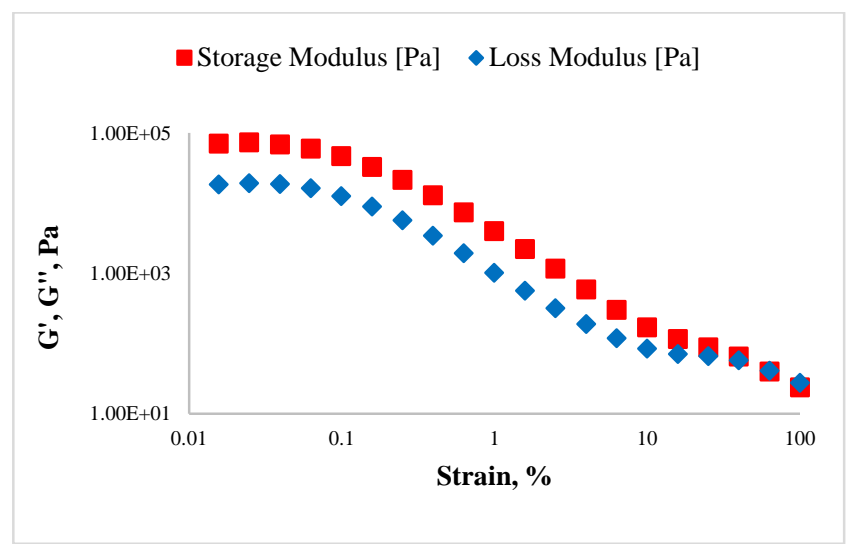

Figure 7. Amplitude-sweep of ghee with a LVE range and the crossover point $G^{\prime}=G^{\prime \prime}$

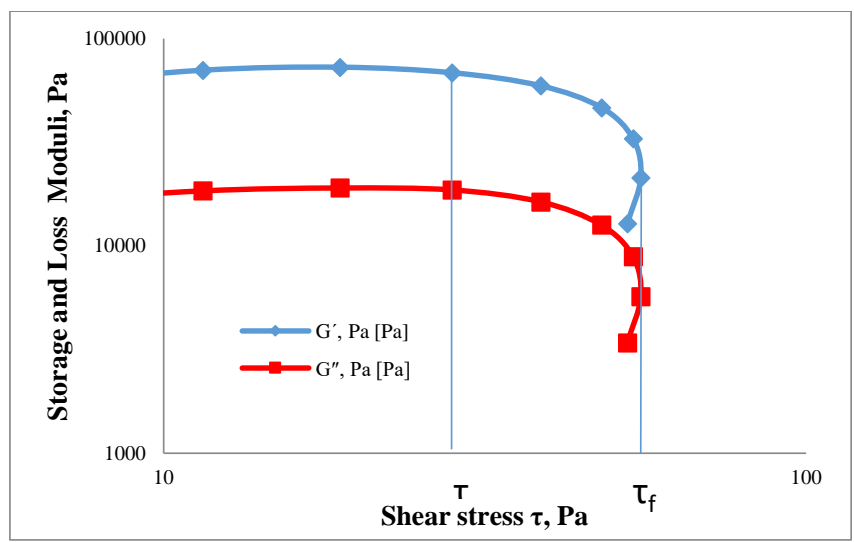

Figure 8. Amplitude sweep, presented with shear stress $\tau$ plotted on the $x$-axis, showing the yield point $\tau_{y}$ at the limit of the LVE region and the flow point $\tau_{f}$ at the crossover point $G^{\prime}=G^{\prime \prime}$.

The amplitude-sweep was performed at $20^{\circ} \mathrm{C}$ for describing the deformation behavior of ghee in the non-destructive deformation range and at determining the upper limit of this range and determining the yield point and the flow point. As shown in Fig. 7 storage and loss moduli are nearly parallel in the lower strain range from 0.01 to $0.1 \%$ strain, this region called Linear Viscoelastic (LVE) region. Rohm (1993) found that the LVE behavior of commercial butter was present up to a critical shear strain of $0.001 \%$ and that structure breakdown due to shear strain between 0.001 and $0.01 \%$ was fully recoverable [17].

Upper LVE range the ghee as nonlinear elastic material do not show linear behavior in any range of stress. However, the storage modulus $\mathrm{G}^{\prime}$ of ghee had higher values than loss modulus $\mathrm{G}^{\prime \prime}$, that indicated the visco-elastic structure with more solid-like behavior that was better described by storage modulus $\mathrm{G}^{\prime}$. These findings are in accordance with Herrera and Hartel (2012), who stated that milk fat has solid-like behavior with higher storage modulus $\mathrm{G}^{\prime}$ (viscoelastic material). Nevertheless, the storage modulus $\mathrm{G}^{\prime}$ of milk fat varied with all processing conditions such as the temperature of crystallization $\left(25\right.$ to $30^{\circ} \mathrm{C}$ ), cooling rate, and agitation rate. Moduli were higher for samples crystallized at a slow cooling rate, decreased with agitation rate, and were lower for the 30 $70 \%$ blend at all processing conditions used [18]. According to Macias Rodriguez (2019), margarine and milk butter at room temperature also behave as elastoplastic substances [9]. In the current study, with increasing deformation the crossover point $\mathrm{G}^{\prime} / \mathrm{G}^{\prime \prime}$ achieved at $51 \%$ strain, after this point the storage modulus $\mathrm{G}^{\prime}$ decreases and is less than loss modulus $\mathrm{G}^{\prime \prime}$, that indicates the inner structure gets softer, the flow of samples commences. Fig. 8 shows that in the region between yield point and flow point, $G^{\prime}>G^{\prime \prime}$. Within this yield zone, the initial structural strength of the LVE region has already decreased but the ghee sample still predominantly displayed the properties of solid matter. The yield point $\tau_{\mathrm{y}}$ (or yield stress) - is the value of the shear stress at the limit of the LVE region. The flow point $\tau_{f}$ (or flow stress) - is the value of the shear stress at the crossover point $G^{\prime}=G^{\prime \prime}$. At higher shear, the viscous portion will dominate and the sample flows. Both values are dependent on the measuring conditions, for example, on the preset (angular) frequency [11]. The flow stress from the rotation test and oscillation test are comparable (53.38; 55.3 Pa, respectively). From these observations, it can be concluded that ghee has solid-like (viscoelastic) and highly strain-dependent behavior at $20^{\circ} \mathrm{C}$.

\section{Conclusion}

Rheological measurements showed that Kyrgyz ghee behaved as a non-Newtonian fluid with viscoelastic properties with yield stress value and the Hershel-Bulkley model was found to be superior in predicting the shear rate-stress data at 20$30^{\circ} \mathrm{C}$ and at $40^{\circ} \mathrm{C}$ the Ostwald model was best-fitted to the flow curves of ghee. According to the hysteresis area analysis, ghee samples performed time-dependent properties at 20$40^{\circ} \mathrm{C}$ which was highly dependent on storage conditions. At fridge temperature Kyrgyz ghee crystallizes and builds up hard consistency with high yield stress. Higher temperatures lead to the melting of fat crystals and time-independent 
Newtonian properties at $50^{\circ} \mathrm{C}$ were measured. Thus, the rheological parameters of the Kyrgyz ghee samples were highly shear and temperature-dependent. The amplitude sweep also showed that the ghee has a viscoelastic structure solid-like and the structural stability was highly straindependent. Obtained rheological parameters are helpful for the establishment and optimization of technological parameters such as transport by pipe or pump and agitation process to produce ghee on the industrial-scale.

\section{References}

[1]. Sserunjogi M.L., Abrahamsen R.K., Narvhus J., “A review paper: Current knowledge of ghee and related products,” International Dairy Journal, 8(8), (1998), 677-688. doi:10.1016/S0958-6946(98)00106-X.

[2]. Gosewade S., Gandhi K., Ranvir S., Kumar A., Lal D., "A study on the physico-chemical changes occurring in ghee ( butter oil ) during storage,” Journal of Dairy Science, 70, (2017), 81-88.

[3]. Mehta B.M., "Ragi (Eleusine coracana L.) - A natural antioxidant for ghee (butter oil)," International Journal of. Food Science and Technology, 41(1), (2006), 8689. doi:10.1111/j.1365-2621.2006.01348.x.

[4]. Alganesh T.G., Yetenayet B.T., "Traditional butter and ghee production, processing and handling in Ethiopia: A review,” African Journal of Food Science, 11(4), (2017), 95-105. doi:10.5897/ajfs2016.1544.

[5]. Sharma H., Zhang X., Dwivedi C., "The effect of ghee (clarified butter) on serum lipid levels and microsomal lipid peroxidation,” An International Quarterly Journal of Research in Ayurveda, 31(2), (2010), 134. doi: 10.4103/0974-8520.72361.

[6]. Suryakumari C., Anusha A., Anitha P., Ravindra D., "Formulation and evaluation of cow ghee as a base fast and sustained release chloroquine phosphate suppositories”, World Journal of Pharmacy and Pharmaceutical Sciences, 3(6), (2014), 1493-1509.

[7]. Tabilo-Munizaga G., Barbosa-Cánovas G. V., "Rheology for the food industry," Journal of Food Engineering, 67, (2005), 147-156. doi: 10.1016/j.jfoodeng.2004.05.062.

[8]. Macias Rodriguez B.A., "Nonlinear rheology of fats using large amplitude oscillatory shear tests," in
Structure-Function Analysis of Edible Fats, Marangoni A.G., Ed., 2nd ed. Urbana: AOCS Press, 2019, pp. 169195. https://doi.org/10.1016/B978-0-12-8140413.00006-X

[9]. Interstate standard for melted butter and milk fat, GOST 32262-2013.

[10]. Rao M.A., "Rheology of fluid and semisolid foods: principles and applications”. New York: Springer Science+Business Media, LLC, 2007.

[11]. Mezger T.G., “The rheology handbook,” Hannover: Vincentz Network, 2011.

[12]. Duhan N., Sahu J.K., Naik S.N., “Temperature dependent steady and dynamic oscillatory shear rheological characteristics of Indian cow milk (Desi) ghee,” Journal of Food Science and Technology, 55(10), (2018), 4059-4066. doi: 10.1007/s13197-0183332-6

[13]. Taghizadeh M., Razavi S.M.A., "Modeling timeindependent rheological behavior of pistachio butter," International Journal of Food Properties, 12(2), (2009), 331-340. doi:10.1080/10942910701772048.

[14]. Ronholt S., Kirkensgaard J.J.K., Pedersen T.B., Mortensen K., Knudsen J.C., "Polymorphism, microstructure and rheology of butter. Effects of cream heat treatment,” Food Chemistry, 135(3), (2012), 17301739. https://doi.org/10.1016/j.foodchem.2012.05.087

[15]. Moorthy A.S., "Melting and solidification of fats," in Structure-Function Analysis of Edible Fats, Marangoni A.G., Ed., 2nd ed. Urbana: AOCS Press, 2018, pp. 101118. https://doi.org/https://doi.org/10.1016/B978-0-12814041-3.00004-6

[16]. Smanalieva, J., Ozbekova, Z., Kulmyrzaev, A., Fischer, P. "Investigation of fatty acid composition, thermal and rheological behavior of yak, cow and horse fats”. Manas Journal of Engineering, 7(1), (2019), 24-33.

[17]. Rohm H., "Rheological behaviour of butter at large deformations,” Journal of Texture Studies, 24, (1993), 139-155.

[18]. Herrera M.L., Hartel R.W., "Effect of processing conditions on physical properties of a milk fat model system: Rheology,” Journal of the American Oil Chemists’ Society, 77(11), (2000), 1189-1196. https://doi.org/10.1007/s11746-000-0185-3. 